\title{
Photonic plasmid stability of transformed Salmonella Typhimurium: A comparison of three unique plasmids Keesla Moulton ${ }^{1}$, Peter Ryan ${ }^{1}$, Donald Lay ${ }^{2}$ and Scott Willard*†1
}

Address: ${ }^{1}$ Department of Animal and Dairy Science, Mississippi State University, Box 9815, Mississippi State, MS 39762, USA and ${ }^{2}$ USDA-ARS, Livestock Behavior Research Unit, 125 S. Russell St. West Lafayette, IN, 47907 USA

Email: Keesla Moulton - kmoulton@ads.msstate.edu; Peter Ryan - pryan@ads.msstate.edu; Donald Lay - Don.Lay@ars.usda.gov; Scott Willard* - swillard@ads.msstate.edu

* Corresponding author †Equal contributors

Published: 27 July 2009

BMC Microbiology 2009, 9:152 doi:10.1/86/147|-2/80-9-152
Received: 7 October 2008

Accepted: 27 July 2009

This article is available from: http://www.biomedcentral.com/147I-2180/9//52

(c) 2009 Moulton et al; licensee BioMed Central Ltd.

This is an Open Access article distributed under the terms of the Creative Commons Attribution License (http://creativecommons.org/licenses/by/2.0), which permits unrestricted use, distribution, and reproduction in any medium, provided the original work is properly cited.

\begin{abstract}
Background: Acquiring a highly stable photonic plasmid in transformed Salmonella Typhimurium for use in biophotonic studies of bacterial tracking in vivo is critical to experimental paradigm development. The objective of this study was to determine stability of transformed Salmonella Typhimurium (S. typh-lux) using three different plasmids and characterize their respective photonic properties.
\end{abstract}

Results: In presence of ampicillin (AMP), S. typh-lux with pCGLS-I, pAKI-lux and pXEN-I plasmids exhibited $100 \%$ photon-emitting colonies over a 10-d study period. Photon emitters of $S$. typh-lux with PCGLS-I, PAKI-lux and PXEN-I without AMP selection decreased over time $(\mathrm{P}<$ 0.05 ), representing only $\mathrm{II} \pm 1 \%, 35 \pm 1 \%$ and $43 \pm 1 \%$, respectively, of original photon emitting properties of the bacterial population by $\mathrm{d} 10$. Photonic emissions were positively correlated with bacterial concentration $(P<0.05)$ for PAKI-lux, PCGLS-I and PXEN-I $(r=0.96,0.98$ and 0.82, respectively). When stratified by high, medium and low density bacteria concentrations, photonic emissions for high density populations containing pAKI-lux, PCGLS-I and pXEN-I resulted in differences of photonic emissions across a range of bacterial concentrations $\left(I \times 10^{7}\right.$ to $1 \times 10^{9}$ CFU, $P<0.05)$ with positive correlations $(P<0.05)$ of $(r=0.72,0.46$ and 0.72 , respectively). The correlation of photonic emissions with bacterial concentrations for samples with medium and low density bacteria (pAKI-lux, pCGLS-I, and pXEN-I plasmids) imaged in tubes were also positively correlated (medium; $r=0.69,0.49,0.46$, low; $r=0.90,0.71,0.68$, respectively; $P>0.05$ ); although photonic emissions across a range of bacterial concentrations were not different $\left(I \times 10^{4}\right.$ to $\mid \times$ $10^{6} \mathrm{CFU}, \mathrm{P}>0.05$ ). For very low density bacterial concentrations imaged in 96 well plates photonic emissions were positively correlated with bacterial concentration $(P<0.05)$ for pAKI-lux, $P C G L S-$ $I$, and PXEN-I plasmids ( $r=0.99,0.99$, and 0.96 , respectively), and photonic emissions across a range of bacterial concentrations $\left(\mathrm{I} \times 10^{3}\right.$ to $\left.\mathrm{I} \times 10^{5} \mathrm{CFU}\right)$ low to high were different in the 96 well plate format $(P<0.05)$.

Conclusion: These data characterize photon stability properties for S. typh-lux transformed with three different photon generating plasmids that may facilitate real-time Salmonella tracking using in vivo or in situ biophotonic paradigms. 


\section{Background}

Researchers are increasingly interested in observing biological processes in real-time. The development of reporter systems such as fluorescence and bioluminescence allows for imaging and measuring of various biological activities. Various reporter plasmids developed from Photorhabdus luminescens and plasmids developed from firefly luciferases are being utilized for in vitro and in vivo bioluminescence research paradigms [1-3] yet comparisons of plasmid functional characteristics and stability post-transformation are not always characterized or compared.

The biochemical basis of the bacterial-bioluminescence system has been characterized and is well documented [4]. Along with the lux genes, antimicrobial genes are added to the gene cassettes for plasmid preparation in bacteria to provide selective pressure (e.g. ampicillin resistance) for procedural manipulations. However, stability of recombinant plasmids is sometimes an issue, as pMG36e-lux-AB was found to be very stable in Lactococcus lactis MG1363, while pMG36e-luxCDABE was unstable in the absence of selective pressure in the form of antibiotic [5] and therefore may not be a suitable plasmid for work where the short term absence of antibiotic selective pressure may not be desired or is not possible (e.g., in vivo imaging).

The plasmid pCGLS- 1 is an insert of approximately $11 \mathrm{~kb}$ of $X$. luminescens DNA and ampicillin is used for selection The genes for production of light encode the two subunits of luciferase and the enzymes of the fatty acid reductase complex [6]. The pAK1-lux plasmid was developed as a broad host range plasmid by using a pBBR1 replicon to constitutively and inducibly express gfpmut $3 a$ and luxCDABE genes from the Plac promoter [7] for gram negative bacterium, and ampicillin is used for selection. Plasmid pXEN-1 is a shuttle plasmid carrying the modified luxABCDE operon for engineering bioluminescent gram positive bacteria. The original gene sequence of gram negative $P$. luminescens lux $C D A B E$ genes are modified to AGGAGG that can be optimally recognized in gram positives. There is no apparent terminator for the $\operatorname{lu} A B B$ $C D E$ operon on the plasmid and ampicillin is used for selection in E. coli while chloramphenicol is used for selection of the autonomous replicating plasmid in gram positives [8].

The objective of this study was to determine the stability of transformed Salmonella Typhimurium (S. typh-lux) using three different plasmids (pAK1-lux, pXEN-1, and pCGLS1 ) in the presence and absence of selective pressure in vitro. In addition, we sought to determine the respective photonic properties (luminescent:bacterial concentration correlations and minimum and maximum luminescent thresholds) of each plasmid using different imaging platforms (e.g. $1.5 \mathrm{ml}$ black microcentrifuge tubes vs 96 well plates, etc.) and by varying concentrations of $S$. typh-lux bacteria.

\section{Methods \\ Transformation and Selection of Salmonella Typhimurium}

Salmonella Typhimurium (ATCC \# 14028; Manassas, VA) were transformed with plasmid pAK1-lux(4), pXEN-1 (Xenogen Bioware $^{\mathrm{TM}}$ ), and pCGLS-1 [6] using an electroporation protocol described in detail previously $[9,10]$. Following transformation, the bacteria were spread on Brilliant Green Agar (BG) + Ampicillin Sodium Salt, (AMP; $2 \mu \mathrm{g} / \mathrm{ml}$; Sigma-Aldrich, Inc. St. Louis, MO) for selection. From the plate both AMP and no AMP Luria Bertani (LB) broth cultures were inoculated to be used in the stability experiment (Experiment 1) and AMP LB broth cultures were used for photonic and bacterial concentration correlations in black microcentrifuge tubes and black 96-well plates (Experiment 2).

\section{Experiment I: Inoculum, imaging, plating and counting procedure for plasmid stability}

One colony (S. typh-lux) was transferred to $20 \mathrm{ml}$ of LB broth and LB + AMP and shaken in an orbital shaker at $37^{\circ} \mathrm{C}$ for $24 \mathrm{~h}$. From each 24 -h inoculum, 2 repetitions of 8 wells filled with $100 \mu$ in respective columns of a black 96-well plate were used for imaging, and 7 wells per plate $(n=2)$ were used for subsequent serial dilution and plating for bacterial counts $(n=14)$. One well was transferred back to an inoculum tube to sub-culture for another $24 \mathrm{~h}$ up to $10 \mathrm{~d}$. All other wells were filled with $100 \mu \mathrm{l}$ of sterile broth. The 96-well plates were then imaged using a XR/ MEGA-10Zero ${ }^{\mathrm{TM}}$ (Stanford Photonics, Inc, Palo Alto, CA) photonic imaging system at $1 \times 1$ binning and an acquisition time of $5 \mathrm{sec}$. Each well was serially diluted in $900 \mu \mathrm{l}$ of LB or LB+AMP broth. Three-dilutions were spread on $\mathrm{BG}$ or $\mathrm{BG}+\mathrm{AMP}$ agar and incubated at $37^{\circ} \mathrm{C}$ overnight. The incubation tubes were placed in a $37^{\circ} \mathrm{C}$ orbital shaker and the imaging, serial dilution, and plating was conducted every $24 \mathrm{~h}$ up to $10 \mathrm{~d}$. On each day following plating, the agar plate colonies were counted, imaged, the number of emitting colonies recorded and bacterial concentrations calculated. The photonic images of the black 96-well plates were analyzed using Image J software (NIH) and reported as relative light units per sec (RLU/s), the emissions from the comparison blank sterile broth wells (i.e., background) were subtracted from the bacterial emitting wells to correct for background photonic emissions. Percent emissions were calculated daily as: (number of emitting colonies/total number of colonies) ${ }^{*} 100$. These procedures were carried out for each of the three plasmids analyzed. 


\section{Experiment 2: Inoculum, imaging, plating and counting procedure for plasmid characterization}

One colony (S. typh-lux) was transferred to $20 \mathrm{ml}$ of LB + AMP and shaken in an orbital shaker at $37^{\circ} \mathrm{C}$ for $24 \mathrm{~h}$. From this inoculum, 6 separate sets were serially diluted $(\mathrm{n}=15)$ as high, medium, and low density bacterial populations in LB+AMP broth (1-ml black microcentrifuge tubes) and prepared for imaging. Another very low density set (with 4 serial dilutions) of $100 \mu$ per well $(n=15)$ were transferred to black 96-well plates for further comparisons of the lower-limits of photonic detection relative to bacterial concentration. The tube sets, including 5 tubes with sterile broth for background correction, were then imaged using a XR/MEGA-10Zero ${ }^{\mathrm{TM}}$ (Stanford Photonics, Inc, Palo Alto, CA) imaging system at $1 \times 1$ binning and an acquisition time of 2 to $30 \mathrm{~s}$. The 96-well plates were imaged under the same parameters, however a $30 \mathrm{~s}$ acquisition time was utilized with these low concentration/low light detection determinations. From each tube or well, $100 \mu \mathrm{l}$ was serially diluted in $900 \mu \mathrm{l}$ of LB or LB+AMP broth. Three-dilutions were then plated on $B G$ or $\mathrm{BG}+\mathrm{AMP}$ agar and incubated at $37^{\circ} \mathrm{C}$ overnight. The following day, the agar plate colonies were counted, imaged, the number of emitting colonies recorded, and bacterial concentrations calculated. The photonic images of the black micocentrifuge tubes and 96-well plates were analyzed using Image J software (NIH) and reported in RLU/ $\mathrm{s}$. The emissions from the comparison blank sterile broth tubes and wells (i.e. background) were subtracted from the bacterial emitting tubes to correct for background photonic emissions. These procedures were carried out for each of the three plasmids analyzed.

\section{Statistical Analysis}

Percent photonic emissions, well photonic emissions, and bacterial concentrations were analyzed over time by repeated measures ANOVA using the mixed procedure. Pearson Correlations were used to determine coefficients for emitting $S$. typh-lux bacterial concentrations and well photonic emissions (SAS 9.1, Cary, NC). Tube photonic emissions and bacterial concentrations in tubes were analyzed by Mixed Procedure with Least Square Means to determine differences. Pearson Correlations were used to determine coefficients for emitting $S$. typh-lux bacterial concentrations and tube or well photonic emissions (SAS 9.1, Cary, NC).

\section{Results and discussion}

Previous research from our laboratory concerning the stability of pAK1-lux plasmid in E. coli over a continual subculture without antibiotic selective pressure indicated a continual gradual decline in the percent of bacterial emissions from $100 \%$ to $66 \%$ by d 8 [10]. Moreover, Salmonella Typhimurium with plasmid pCGLS-1 and pAK1-lux were similarly evaluated for stability and indicated a decline in percent of photonic emissions by day 6 of 39 and 55.5\%, respectively [11]. Our current results are similar with a continual decline in percent of emissions for all plasmids, however by day 6 the plasmid pCGLS-1 percent emissions were lower than pAK1-lux or pXEN-1, and much lower by day 10 (Table 1 and Figure 1). Moreover, a decline in photonic emissions as well as a decrease in bacterial concentration from $\mathrm{d} 0$ to 10 in Experiment 1 (Table 2) resulted in good correlations between bacterial numbers and photonic emissions (Figure 2). Another bacterium, Edwardsiella ictaluri has been imaged in vitro and similarly evaluated with the pAK1-lux plasmid resulting with a decline in bioluminescence after 10 days of subculturing without antibiotic selective pressure and appears to have a half-life of 18 days [7]. Several Salmonella strains were also similarly evaluated without antibiotic selective pressure with the pAK1-lux plasmid and results also demonstrated a continued linear decline of bioluminescence with a half-life estimation of 7 days [12].

A separate study has also evaluated the luminescence signal in broth using the pCGLS-1 plasmid in Pseudomonas aeruginosa at various densities through measurements from a luminometer. The detection of the luminescence signal was linearly proportional to bacterial colony forming units [8], and agrees with the results for Experiment 2 in the present study with high and low bacterial densities in broth culture with all three plasmids (pCGLS-1, pXEN1 and pAK1-lux) in both $1 \mathrm{ml}$ black centrifuge tube or black 96-well plate formats (Table 3). Other scientists using a luminescence assay, via a luminometer plate reader, determined sensitivity as a 3-log reduction in viability whereas the colony-forming unit assay can measure a 6-log reduction in viability [8]. It also appeared that a cytotoxic insult to bacteria causes a loss of viability more readily than it caused loss of luminescence. The decrease in luminescence may be due to exhaustion of ATP supplies from the bacteria (needed for the luciferase enzyme to make luminescence), which cannot be replenished if the cells are fatally damaged [8].

When pAK1-lux was used in Edwardsiella ictaluri through 5 orders of magnitude, the relationship of bacterial density and bioluminescence was a linear correlation $(\mathrm{r}=$ 0.99 ) with a minimum detectable number of bacteria in a 96-well plate format of $2500 \mathrm{CFU} / \mathrm{ml}$ [7]. Bacteria numbers and bioluminescence correlations were very good ( $\mathrm{r}$ $=0.99$ ) in 12 strains of Salmonella transferred with the pAK1-lux plasmid and for a majority of the strains the minimum detectable bacterial numbers was less than $1500 \mathrm{CFU} / \mathrm{ml}$ [12]. The above studies were similar to Experiment 2 results of good correlations for pAK1-lux and pXEN-1 evaluated in the $1 \mathrm{ml}$ black centrifuge tube format as well as the black 96-well plate format (Figure 3 and 4). However the plasmid pCGLS-1 did not have as 


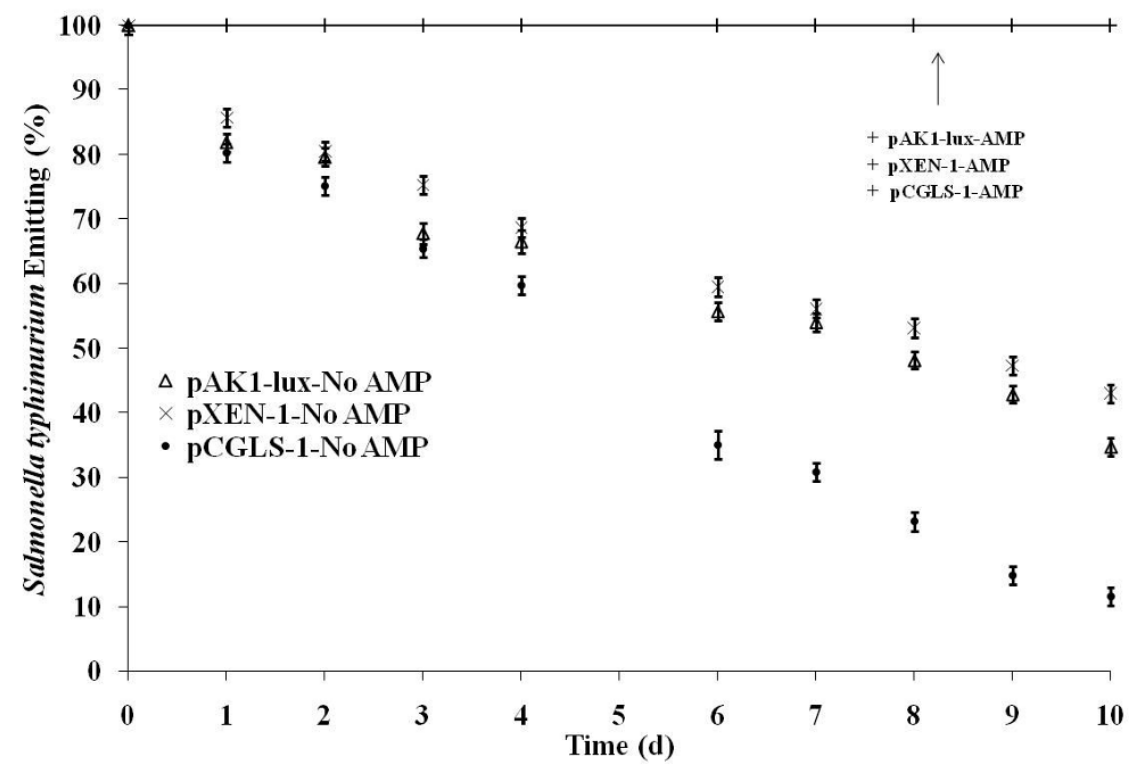

Figure I

Percentage of bacteria emitting photons. Percentage of photon-emitting Salmonella typhimurium and lux-plasmid (pAKIlux, PXEN-I, or PCGLS-I) following imaging in the presence of ampicillin and without ampicillin selection for 10 consecutive days in vitro $(P<0.05)$.

good a correlation as in the above experiments or relative to the other plasmids in our study for the $1 \mathrm{ml}$ black tube format (Figure 3). We also noted that the minimum detectable concentration for the $1 \mathrm{ml}$ black centrifuge tube is much higher, whereas the minimum detectable concentration for the black 96-well plate format is similar to the above referenced studies $[7,8]$ (Table 3 ). Other sci-

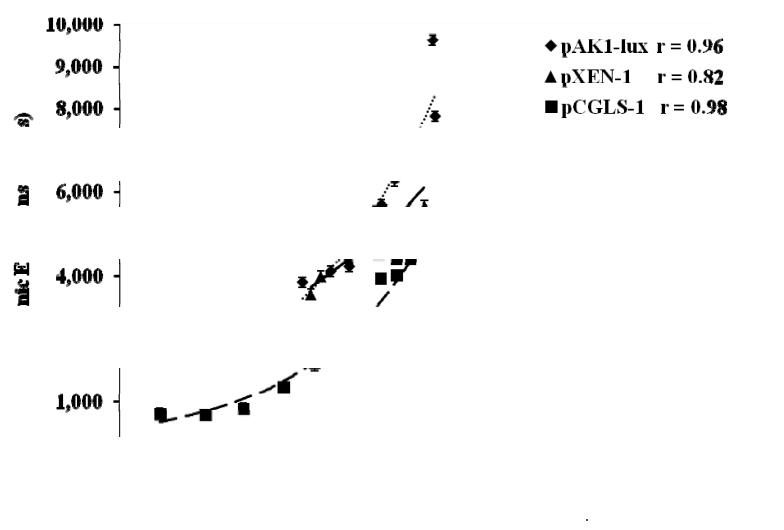

Figure 2

Correlation between luminescence and bacterial numbers. The correlation of photon-emitting Salmonella typhimurium and lux plasmid (pAKI-lux, pXEN-I, or pCGLSI) following imaging without ampicillin selection in wells of 96-well plate $(\mathrm{P}<0.05)$. entists using ten-fold dilutions of a mid-log-phase culture of Escherichia coli (pCGLS-1) assayed for bioluminescence using a conventional microtiter luminometer and an ICCD camera obtained similar bioluminescence curves for each system [13]. The dynamic range of the ICCD camera was between approximately 2.6 and 6 log units. The bioluminescence curves were found to closely correlate with viable cell counts, yielding correlation coefficients of 0.98 for both the luminometer and ICCD, respectively,

Table I: Stability of luminescent bacteria evaluated as percent emitting bacteria.

\begin{tabular}{|c|c|c|c|}
\hline \multirow[b]{2}{*}{ Plasmid Type } & \multicolumn{3}{|c|}{$\begin{array}{l}\text { Luminescent Salmonella typhimurium } \\
\text { Day of Culture (\% of Total Colonies) }\end{array}$} \\
\hline & 0 & 6 & 10 \\
\hline \multicolumn{4}{|l|}{ pAKI-lux } \\
\hline \% Emitters & 100 & $56 \pm\left.\right|^{a, x}$ & $35 \pm\left.\right|^{b, x}$ \\
\hline$\%$ Non-Emitters & 0 & $44 \pm 1$ & $65 \pm 1$ \\
\hline \multicolumn{4}{|l|}{ pXEN-I } \\
\hline \% Emitters & 100 & $60 \pm\left.\right|^{a}, y$ & $43 \pm\left.\right|^{b, y}$ \\
\hline$\%$ Non-Emitters & 0 & $40 \pm 1$ & $57 \pm 1$ \\
\hline \multicolumn{4}{|l|}{ pCGLS-I } \\
\hline \% Emitters & 100 & $35 \pm 2^{\mathrm{a}, \mathrm{z}}$ & $I I \pm\left.\right|^{b, z}$ \\
\hline$\%$ Non-Emitters & 0 & $65 \pm 2$ & $89 \pm 1$ \\
\hline
\end{tabular}

Superscripts differ within plasmid a,b $(P<0.05)$.

Superscripts differ between plasmids $x, y, z(P<0.05)$.

Stability of luminescent Salmonella typhimurium with three different plasmids (pAKI-lux, pXEN-I, and pCGLS-I); Percent emitting and non-emitting evaluations at day 0,6 , and 10 of in vitro culturing without ampicillin selection. 
Table 2: Stability of luminescent bacteria evaluated as emitting concentration and luminescence detection.

\begin{tabular}{|c|c|c|c|}
\hline \multirow[b]{2}{*}{ Plasmid Type } & \multicolumn{3}{|c|}{$\begin{array}{l}\text { Luminescent Salmonella typhimurium } \\
\text { Day of Culture (Emitting Concentration; CFU) }\end{array}$} \\
\hline & 0 & 6 & 10 \\
\hline pAKI-lux & $1.2 \times 10^{8} \pm 7.2 \times 10^{6 a, x}$ & $7.4 \times 10^{7} \pm 1.1 \times 10^{7 b, x}$ & $4.2 \times 10^{7} \pm 7.2 \times 10^{6 c, x}$ \\
\hline PXEN-I & $9.7 \times 10^{7} \pm 7.2 \times 10^{6 a, x}$ & $7.0 \times 10^{7} \pm 7.8 \times 10^{6 b, x}$ & $4.4 \times 10^{7} \pm 7.2 \times 10^{6 c, x}$ \\
\hline \multirow[t]{2}{*}{ PCGLS-I } & $1.2 \times 10^{8} \pm 7.2 \times 10^{6 a, x}$ & $4.6 \times 10^{7} \pm 1.1 \times 10^{7 b, y}$ & $1.3 \times 10^{7} \pm 7.2 \times 10^{6 c, y}$ \\
\hline & \multicolumn{3}{|c|}{$\begin{array}{l}\text { Luminescent Salmonella typhimurium } \\
\text { Day of Culture (Photonic Detection; RLU/s) }\end{array}$} \\
\hline Plasmid Type & 0 & 6 & 10 \\
\hline pAKI-lux & $78 \mid 1 \pm 159 a, x$ & $5550 \pm 159 b, x$ & $3839 \pm 158 c, x$ \\
\hline pXEN-I & $7 \mid 49 \pm 159 a, y$ & $4898 \pm\left. 17\right|^{b, y}$ & $3552 \pm 159 c, y$ \\
\hline pCGLS-I & $4753 \pm 159 a, z$ & $1921 \pm 242^{b, z}$ & $708 \pm 159 c, z$ \\
\hline
\end{tabular}

Superscripts differ within plasmid a,b,c $(P<0.05)$.

Superscripts differ between plasmids $x, y, z(P<0.05)$.

Stability of luminescent Salmonella typhimurium with three different plasmids (pAKI-lux, pXEN-I, and pCGLS-I) in 96-well format (I00 $\mu$ I/well);

Percent emitting and non-emitting evaluations at day 0,6 , and 10 of in vitro culturing without ampicillin selection.

and is similar to results from Experiment 2 in the present study (Figure 3 and 4). The sensitivity of the ICCD camera system was also found to be higher than that of the luminometer, detecting a lower limit of approximately 400 cells with a 1-min signal accumulation time as compared to 104 cells shown with the luminometer [13]. From Experiment 2, the detection of the lower limit of bacterial cells is higher using a $30 \mathrm{~s}$ accumulation of signal than the above studies that used a $1 \mathrm{~min}$ accumulation signal (Table 3) which is likely the direct result of camera sensi- tivity. Other scientists have evaluated the minimum number of $S$. aureus RN4220 pXen-1 detectable using a photon-counting ICCD camera. Approximately $400 \mathrm{CFU}$ were detected in the black 96-well plate format. However, using a more sensitive liquid nitrogen-cooled integrating CCD camera (IVIS Imaging system), detection was as few as 80 CFU (5) which is different from the results of Experiment 2 when detecting very low concentrations in the 96well format of approximately 1,000 CFU (Table 3).

Table 3: Detection limits of luminescent Salmonella typhimurium.

\begin{tabular}{|c|c|c|}
\hline Item & Bacterial concentration (CFU) & Photonic emissions (RLU/s) \\
\hline \multicolumn{3}{|c|}{ Black tube format (Iml) upper limit ( $2 \mathrm{~s}$ acquisition time) } \\
\hline Background (used for subtraction of sample) & - & 39 \\
\hline pAKI-lux & $1.1 \times 10^{8} \pm 1.0 \times 10^{7}$ & $7,470 \pm 136$ \\
\hline pCGLS-I & $6.2 \times 10^{7} \pm 1.2 \times 10^{7}$ & $6,168 \pm 167$ \\
\hline PXEN-I & $1.0 \times 10^{8} \pm 1.0 \times 10^{7}$ & $7,016 \pm 136$ \\
\hline \multicolumn{3}{|c|}{ Black tube format $(1.0 \mathrm{ml})$ lower limit ( $2 \mathrm{~s}$ acquisition time) } \\
\hline Background (used for subtraction of sample) & - & 33 \\
\hline pAKI-lux & $2.7 \times 10^{6} \pm 1.0 \times 10^{7}$ & $278 \pm 136$ \\
\hline pCGLS-I & $1.8 \times 10^{6} \pm 1.0 \times 10^{7}$ & $327 \pm 136$ \\
\hline pXEN-I & $5.1 \times 10^{6} \pm 1.0 \times 10^{7}$ & $|48 \pm| 4 \mid$ \\
\hline Item & Bacterial concentration (CFU) & Photonic emissions (RLU/s) \\
\hline \multicolumn{3}{|c|}{ 96-well black plate format ( $100 \mu \mathrm{l})$ lower limit (30 s acquisition time) } \\
\hline Background (used for subtraction of sample) & - & 6 \\
\hline pAKI-lux & $3.8 \times 10^{3} \pm 2.8 \times 10^{3}$ & $2.0 \pm 1.3$ \\
\hline pCGLS-I & $2.9 \times 10^{3} \pm 2.8 \times 10^{3}$ & $1.1 \pm 1.3$ \\
\hline pXEN-I & $2.8 \times 10^{3} \pm 2.7 \times 10^{3}$ & $1.1 \pm 1.2$ \\
\hline
\end{tabular}

Luminescent Salmonella typhimurium with three different plasmids (PAKI-lux, pXEN-I, and PCGLS-I); upper and lower detection limits for black tube format $(2 \mathrm{~s}$ acquisition time) and low detection limits for black 96 -well plate format ( $30 \mathrm{~s}$ acquisition time). The results below are bacterial concentration means \pm standard error of the mean and photonic emissions means \pm standard error of the mean. 

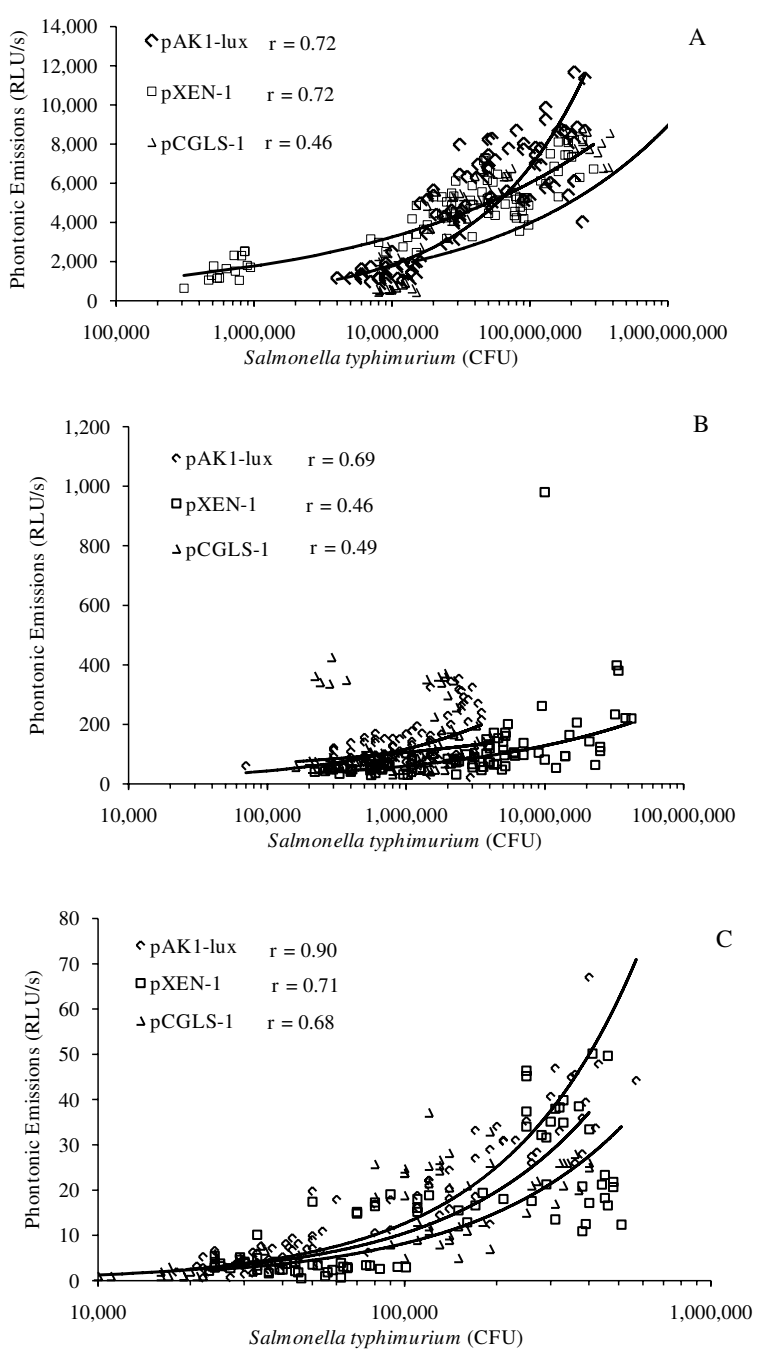

Figure 3

Correlation between luminescence and bacterial numbers at various densities in black microcentrifuge tubes. Correlation of photon-emitting Salmonella typhimurium and lux plasmid (pAKI-lux, pXEN-I, or pCGLS-I) following imaging of I $\mathrm{ml}$ aliquots in black microcentrifuge tubes (Panel $A$ ) high density $(P>0.05)$, (Panel $B$ ) medium density $(P<0.05)$, (Panel $C)$ low density of bacteria $(P>$ 0.05).

\section{Conclusion}

These data characterize the photon stability properties for Salmonella Typhimurium transformed with three different photon generating plasmids. Salmonella Typhimurium that is transformed with pAK1-lux and pXEN-1 bioluminescent plasmids are more stable and have better correlations with actual bacterial concentration than the pCGLS-1 plasmid. However for short-term evaluations of 1 to 6 days, all three plasmids may permit real-time Salmonella tracking using in vivo or in situ biophotonic paradigms

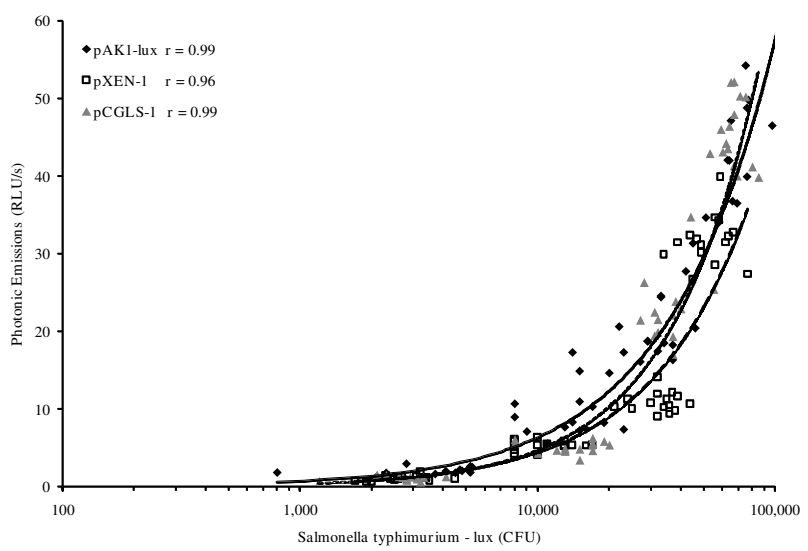

Figure 4

Correlation between luminescence and bacterial numbers at a very low density in black 96-well plate. Correlation of photon-emitting Salmonella Typhimurium and lux plasmid (pAKI-lux, pXEN-I, or pCGLS-I) following imaging of $100 \mu$ aliquots in wells of black 96 -well plate $(P<$ $0.05)$.

where antibiotic selective pressure to maintain plasmid incorporation may not be feasible.

\section{Authors' contributions}

KM conceived the study and participated in the design of the study. KM carried out the bacterial-plasmid transformation, participated in the imaging, bacterial serial dilution, plating, counting statistical analysis, data interpretation and drafted the manuscript. SW participated in the design of the study and assisted in statistical analysis as well as helped to draft the manuscript. DL and PR participated in interpretation of data and helped to draft and critically revise the manuscript. All authors read and approved the final manuscript.

\section{Acknowledgements}

This work was supported by grants from USDA-ARS-funded Biophotonics Initiative \#58-6402-3-0120. The authors also gratefully acknowledge the Department of Animal and Dairy Sciences and the Mississippi Agriculture and Forestry Experiment Station for study resource support.

\section{References}

I. Contag PR: Whole-animal cellular and molecular imaging to accelerate drug development. Drug Discov Today 2002, 7:555-562.

2. Frank SJ, Wang X, He K, Yang N, Fang P, Rosenfeld RG, et al.: In vivo imaging of hepatic growth hormone signaling. Mol Endocrinol 2006, 20:2819-2830.

3. Ryan PL, Youngblood RC, Harvill J, Willard S: Photonic monitoring in real time of vascular endothelial growth factor receptor 2 gene expression under Relaxin-induced conditions in a novel murine wound model. Ann NY Acad Sci 2005, 1041:398-4I4.

4. Meighen EA: Genetics of bacterial bioluminescence. Annu Rev Genet 1994, 28: I 17-139. 
5. Jiang A, Wang H, Lee N, Yang G, Griffiths MW: Biological characteristics of luminescent Lactococcus lactis transformed with lux genes. Food Res Int 2006, 39:426-432.

6. Frackman S, Anhalt $\mathrm{M}$, Nealson $\mathrm{KH}$ : Cloning, organization and expression of the bioluminescence genes of Xenorhabdus luminescens. J Bacteriol 1990, 172:5767-5773.

7. Karsi A, Menanteau-Ledouble S, Lawrence ML: Development of bioluminescent Edwardsiella ictaluri for noninvasive disease monitoring. FEMS Microbiol Lett 2006, 260:216-223.

8. Francis KP, Joh D, Bellinger-Kawahara C, Hawkinson MJ, Purchio TF, Contag PR: Monitoring bioluminescent Staphylococcus aureus infections in living mice using a novel luxABCDE construct. Infect Immun 2000, 64(6):3594-3600.

9. Moulton KE, Lovell F, Williams E, Ryan P, Lay D, Jansen D, Willard S: Use of glycerol as an optical clearing agent for enhancing photonic transference and detection of Salmonella Typhimurium through porcine skin. J Biomed Optics 2006, I I(5):054027-054027.

10. Moulton K, Ryan P, Christiansen D, Hopper R, Klauser C, Bennett W, Rodts-Palenik S, Willard S: Ex vivo bioluminescence imaging of late gestation ewes following intrauterine inoculation with lux-modified Escherichia coli. Comp Immunol Microbiol Infect Dis 2008.

II. Williams E, Moulton K, Moore D, McGee M, Lovell F, Couvillion S, Ryan P, Lay D, Willard S: Photonic properties of transformed Salmonella Typhimurium: Plasmid stability and concentration dependency. J Anim Sci 2006, 84(Suppl 2):27.

12. Karsi A, Howe K, Kirkpatrick TB, Wills R, Bailey RH, Lawrence ML: Development of bioluminescent Salmonella strains for use in food safety. BMC Microbiology 2008, 8: I0.

13. Rocchetta HL, Boylan CJ, Foley JW, Iversen PW, LeTourneau DL, McMillian CL, Contag PR, Jenkins DE, Parr TR Jr: Validation of a noninvasive, real-time imaging technology using bioluminescent Escherichia coli in the neutropenic mouse thigh model of infection. Antimicrob Agents Chemother 200I, 45(I):I29-137.

Publish with Bio Med Central and every scientist can read your work free of charge

"BioMed Central will be the most significant development for disseminating the results of biomedical research in our lifetime. "

Sir Paul Nurse, Cancer Research UK

Your research papers will be:

- available free of charge to the entire biomedical community

- peer reviewed and published immediately upon acceptance

- cited in PubMed and archived on PubMed Central

- yours - you keep the copyright

Submit your manuscript here:

http://www.biomedcentral.com/info/publishing_adv.asp
BioMedcentral 